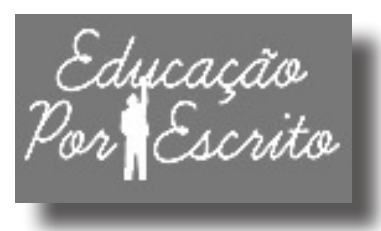

RESENHA

\title{
Durkheim, educação e sociologia
}

Durkheim, education and sociology

José Luís Schifino Ferraroa

\section{Editor}

Maria Inês Côrte Vitoria PUCRS, RS, Brasil

\section{Editor Executivo}

Pricila Kohls dos Santos PUCRS, RS, Brasil

\section{Equipe Editorial}

Rosa Maria Rigo PUCRS, RS, Brasil

Carla Spagnolo PUCRS, RS, Brasil Martha Luci Sozo PUCRS, RS, Brasil Dirce Hechler Herbertz PUCRS, RS, Brasil

\section{ISSN 2179-8435}

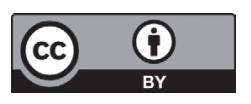

Este artigo está licenciado sob forma de uma licença Creative Commons Atribuição 4.0 Internacional, qu qualquer meio, desde que a publicacăa original seja corretamente citada. http://creativecommons.org/licenses/by/4.0/deed.pt BB

\section{RESENHA DE:}

DURKEIM, Émile. Educação e sociologia. Rio de Janeiro: Editora Vozes, 2013.

É mile Durkheim (1858-1917) inicia sua obra intitulada Educação e sociologia promovendo uma discussão a respeito da pergunta “o que é educação?". Logo de início, o autor faz uma delimitação. Explicita que a concepção de educação que ele toma como referência diz respeito à ação que os homens imprimem sobre os próprios homens. Dentro desta lógica ainda ressalta que "a ação entre homens pertencentes à mesma faixa etária diferem da que os adultos exercem sobre os mais jovens" (DURKHEIM, p. 43, 2013). Ou seja, a concepção de educação está atrelada à preparação das gerações atuais para a vida social realizada pelas gerações anteriores.

Ainda, ao citar Kant e o seu modo de entender a educação como possibilidade de atingir "toda a perfeição a que se é capaz", Durkheim faz uma crítica ao fato de que nem todas as potencialidades de um ser humano podem ser elevadas de maneira semelhante. O simples fato de existirem diferentes "gêneros de vida", "diferentes potencialidades", impede que um ser humano atinja à perfeição por meio do movimento harmônico de suas faculdades. Para o autor, "a harmonia perfeita não pode ser apresentada como objetivo final da educação" (DURKHEIM,

\footnotetext{
a Doutor em Educação, professor da Faculdade de Biociências e do Programa de Pós-graduação em Educação em Ciências e Matemática da Pontifícia Universidade Católica do Rio Grande do Sul (PUCRS).
} 
p. 45, 2013). Segundo ele, isto não seria completamente realizável: "nem todos nós fomos feitos para refletir; são precisos homens de sensação e ação. Ao contrário, são precisos outros cujo trabalho seja pensar" (DURKHEIM, p. 44, 2013). A distinção entre pensamento - como algo desprendido do movimento - e ação - como possibilidade carregada de multiplicidades e formas - se apresenta como espécie de ruptura entre ambos.

Ainda, Durkheim faz uma crítica à concepção utilitarista de James Mill que concebe a educação como tentativa de transformar os indivíduos como "instrumentos de felicidade" para si e para os outros, visto que a felicidade é algo subjetivo (DURKHEIM, p. 45, 2013). Ao trazer exemplos de modelos educacionais nas pólis gregas e latinas, na Roma antiga, na Idade Média e no Renascimento, ele ressalta que não existe uma educação ideal.

[...] na verdade, cada sociedade, considerada em determinado momento de seu desenvolvimento, tem um sistema de educação que se impõe aos indivíduos como uma força geralmente irresistível (DURKHEIM, p. 47-48, 2013).

Há um viés histórico muito forte impregnado à questão educativa. Durkheim coloca que os sistemas educativos ao se desenvolverem sempre dependeram seja da religião, da organização política, do desenvolvimento das ciências, do estado da indústria. O descolamento destes sistemas das causas históricas seria torná-los incompreensíveis. Neste sentido, a educação para uma vida de costumes acaba por ser uma construção social. Ambos são produtos de uma vida comum refletindo seus anseios e necessidades (DURKHEIM, p. 48, 2013).

De acordo, então, com a premissa inicial - de que a educação necessita de um "encontro face a face" entre jovens e adultos, para que estes exerçam ações sobre os primeiros - Durkheim empreende um observar sobre a natureza desta ação educativa (DURKHEIM, p. 50, 2013). Segundo ele, a natureza múltipla diz respeito ao fato de que em uma sociedade possa haver mais de um tipo de sistema educativo. Ainda, se a sociedade em questão for dividida em castas, a educação para cada uma delas será diferente, apresentará variações - princípio da singularidade - mas isto não exclui o fato de que, anterior a isto, possam existir princípios educacionais comuns que balizam a educação de todos antes das diferenças se tornarem realidade (DURKHEIM, p. 50, 2013).

Após estas colocações, Durkheim observa:

[...] cada sociedade elabora um ideal de homem, ou seja daquilo que ele deve ser tanto do ponto de vista intelectual quanto físico e moral; que este ideal é, em certa medida, o mesmo para todos os cidadãos; que a partir de certo ponto ele se diferencia de acordo com os meios singulares que toda a sociedade compreende em seu seio (DURKHEIM, p. 52, 2013). 
E então enuncia:

A educação é a ação exercida pelas gerações adultas sobre aquelas que ainda não estão maturas para a vida social. Ela tem como objetivo suscitar e desenvolver na criança um certo número de estados físicos, intelectuais e morais exigidos tanto pelo conjunto da sociedade política quanto pelo meio específico ao qual ela está destinada em particular (DURKHEIM, p. 53-54, 2013).

Com isto percebe-se uma consequência social à definição, pois neste sentido empregado por Durkheim, daquilo que se entende por educação, há uma "socialização metódica das novas gerações" (DURKHEIM, p. 54, 2013). É muito simples de se observar isto, segundo o próprio autor, quando afirma que na natureza congênita do ser humano não estão inscritas leis que o fazem obedecer. Isto é um efeito das forças morais que pautam a regulação da sociedade, as quais seus sistemas educativos corroboram perpetrando-as. E são estas forças morais que fizeram o homem sentir sua inferioridade e a necessidade de submeter-se (DURKHEIM, p. 55, 2013).

Pelo fato de que a criança quando nasce traz consigo apenas as marcas da hereditariedade, sua natureza pessoal, se tipificando ainda como um "ser egoísta e associal", cabe a educação revelar-lhe as potencialidades. Descortiná-las, para uma vida regulada em sociedade, indo além, pois este movimento é capaz de criar novos homens: a virtude criadora da educação humana (DURKHEIM, p. 55, 2013). A educação é um instrumento de transmissão de aptidões necessárias à vida social (DURKHEIM, p. 56, 2013).

Em assim sendo, pode-se discutir o papel do Estado no processo educativo. Ao mesmo tempo em que a educação é de interesse da sociedade, a sociedade é de interesse da educação em uma via de mão dupla. Durkheim aponta a necessidade da sociedade "lembrar ao professor ideias e sentimentos" que devem ser arraigados durante a formação das crianças (DURKHEIM, p. 62, 2013). Assim surge a tarefa educativa: promover uma "comunhão de ideias e sentimentos entre cidadãos". Isto além de ser o que torna uma sociedade possível, evita que a educação fique a mercê de arbitrariedades ou "vontades individuais" (DURKHEIM, p. 63, 2013). O Estado, então, aparece como o verificador de princípios essenciais e garantidor de seu ensino nas escolas (DURKHEIM, p. 64, 2013).

Ainda, é preciso perceber a educação como questão de autoridade. Ao conduzir-nos ao abandono de nossa condição de natureza inicial, é preciso que exerçamos uma forte repressão contra nós mesmos com o intuito de nos "subordinarmos a fins mais elevados" (DURKHEIM, p. 70-71, 2013). O autor ressalta que a educação em sua conotação de autoridade não diz respeito à "violência ou repressão", mas a uma primazia moral (DURKHEIM, p. 72, 2013). Esta autoridade, segundo Durkheim, deve ser sentida pelo professor para que ele consiga, exatamente, transmitir este sentimento acreditando não em si, mas na grandeza de sua tarefa como educador (DURKHEIM, p. 72, 2013). É essencial a percepção de que a liberdade deriva da "autoridade bem aplicada", 
pois segundo Durkheim, ser livre "significa ter autocontrole e agir guiado pela razão e cumprir o seu dever" (DURKHEIM, p. 73, 2013).

A criança deve, portanto, estar acostumada a reconhecer a autoridade na palavra do educador e a respeitar a sua superioridade. Esta é a condição para que mais tarde ela a reencontre sem sua consciência e acate o que ela prescrever (DURKHEIM, p. 73, 2013).

Na segunda parte de sua obra, Durkheim trata da natureza e método da Pedagogia. Já de início, sua preocupação é diferenciar a educação da Pedagogia. Se a educação é uma ação exercida por adultos - pais e professores - sobre as crianças, a Pedagogia consiste "não em ação, mas em teorias", maneiras de conceber a educação, não de praticála. A pedagogia consiste em uma maneira de refletir sobre a educação (DURKHEIM, p. 75, 2013). Isto tem reflexo em uma perspectiva de continuidade inerente às práticas educativas e também a certa descontinuidade, partindo do princípio que a Pedagogia pode assumir caráter intermitente (DURKHEIM, p. 76, 2013).

Durkheim explicita o caráter disciplinar científico das "coisas" relacionadas à educação (DURKHEIM, p. 76, 2013). O autor justifica a cientificidade por três motivos: o primeiro diz respeito a possibilidade de observar fatos já concluídos, ou seja, tem um objeto bem delimitado; o segundo diz respeito a homogeneidade dos fatos que faz com que se possam estabelecer categorias para enquadrá-los, classificá-los; e o terceiro é condizente ao interesse em conhecer fatos, os quais tais objetos de interesse estão implicados. É por estes motivos que a educação apresenta as características de uma ciência (DURKHEIM, p. 77, 2013).

De fato, a educação vigente em determinada sociedade e considerada em determinado momento de sua evolução é um conjunto de práticas, maneiras de agir e costumes que constituem fatos perfeitamente definidos e tão reais quanto os outros fatos sociais (DURKHEIM, p. 78, 2013).

Ainda, o autor reforça a relação educação/sociedade ao afirmar a impossibilidade de alguém tentar imprimir determinada educação a um filho que não obedeça ao jogo de regras vigentes na sociedade.

Não adianta acreditar que podemos educar nossos filhos como quisermos. Somos obrigados a seguir as regras reinantes no meio social em que vivemos. A opinião nos impõe este comportamento, e a opinião é uma força moral cujo poder opressivo não é menor do que o da força física (DURKHEIM, p. 78, 2013).

Durkheim ressalta ainda que qualquer tentativa de infração às forças morais tem consequências e por causa de sua superioridade dificilmente sairemos vencedores deste embate. Segundo ele é como se estivéssemos "mergulhados em 
uma atmosfera de ideias e sentimentos coletivos" que não podem ser modificados à vontade (DURKHEIM, p. 78-79, 2013). As práticas educativas contribuem para a manutenção de um status quo de determinadas regras sociais e o papel das gerações anteriores passa a ser o de preparar as novas gerações para se adaptarem à vida em um determinado contexto social (DURKHEIM, p. 79, 2013).

É por isto que se pode estabelecer um determinado tipo de prática educativa e relacioná-lo com uma determinada organização de sociedade. Nas tribos a educação é difusa para todo o clã e realizada por anciãos, na Índia e no Egito havia sacerdotes que educavam -"atributo do poder sacerdotal" -, que instruíam conhecimentos que de alguma forma estão imbricados nos discursos religiosos (DURKHEIM, p. 80-81, 2013). Nas pólis gregas e latinas será encontrada uma repartição: parte da educação fica a cargo do Estado, outra parte da família (DURKHEIM, p. 81, 2013). O Estado ao substituir o poder sacerdotal na condução das práticas educativas faz com que comecem a surgir sujeitos, protagonistas laicos, como os filósofos da Grécia Antiga que passam a dominar também o conhecimento científico tornando-se aptos à instruírem: "os grammateus de Atenas eram simples cidadãos, sem ligações oficiais ou caráter religioso" (DURKHEIM, p. 81, 2013).

Ainda, sobre as teorias pedagógicas, Durkheim coloca que consistem em reflexões diferentes, pois não buscam o mesmo objetivo e nem empregam os mesmos métodos (DURKHEIM, p. 83, 2013). Observa que seu objetivo não seria uma descrição do que existiu, do que foi, mas aponta para o devir, sobre como devem ser decretados futuros preceitos de conduta. Apontam: "eis o que deve ser feito" (DURKHEIM, p. 83, 2013). A Pedagogia aparece então como algo distinto ao que seria a Ciência da Educação. Poderia ser uma arte na medida em que a arte seria "todo atributo de uma reflexão que não é ciência", mas Durkheim prefere reservar ao termo "arte" tudo aquilo que é "prática pura sem teoria" (DURKHEIM, p. 83-84, 2013).

Uma arte é um sistema de maneiras de agir adequadas a fins especiais e resultantes ou de uma experiência tradicional transmitida pela educação ou da experiência pessoal do indivíduo. Só se pode adquiri-las mexendo com as coisas sobre as quais a ação deve ser exercida e agindo por si mesmo. Sem dúvida, pode acontecer de a arte ser guiada pela reflexão, mas a reflexão não é um elemento essencial à arte, visto que ela pode existir sem esta última (DURKHEIM, p. 85, 2013).

Observa-se que, neste sentido, tomando Durkheim como referência, concebe-se a possibilidade da educação sem estar condicionada verdadeiramente a existência de uma pedagogia. Mas o que se torna inevitável é que a reflexão sobre uma prática educativa - "processo de ação" - acaba sempre por adquirir um status futuro de teoria. A Pedagogia "reflete sobre os sistemas de educação" (não os estuda cientificamente) para fornecer ao educador, ideias que possam de alguma forma dirigi-lo (DURKHEIM, p. 86, 2013). 
A partir de tudo o que foi colocado, Durkheim ressalta a possibilidade da Pedagogia - como teoria prática apoiar-se sobre a Ciência da Educação e a Sociologia. No primeiro caso, para "saber o que a educação deve ser" (sua natureza), já com relação ao apoio sociológico um reforço para fixar objetivos e definir métodos (DURKHEIM, p. 87, 2013). Com relação ao papel do pedagogo, seria o de reduzir ao mínimo as chances de erro a partir da junção de fatos instrutivos com o máximo de método (DURKHEIM, p. 88, 2013). Eis a importância da pedagogia: diminuir a disparidade da defasagem entre sistemas escolares e necessidades atuais, restabelecendo a harmonia entre ambos, um "auxiliar constante e indispensável da educação" (DURKHEIM, p. 89, 2013). Em tempos de práticas educativas cada vez menos impessoais, a Pedagogia ganha cada vez mais força sendo elemento indispensável. Mas é preciso ressalvar:

[...] o pedagogo não tem de construir de alto a baixo um sistema de ensino, como se já não existisse um antes dele, devendo, ao contrário, empenhar-se, sobretudo em conhecer e compreender o sistema de sua época - esta é a condição para que ele esteja apto a usá-lo com discernimento e julgar o que pode estar errado nele (DURKHEIM, p. 91, 2013).

Compreender um sistema de ensino também implica em ação diagnóstica para poder modificá-lo em uma perspectiva futura, observar aspirações para outros/novos ideais educativos no contexto de realidade escolar (DURKHEIM, p. 92, 2013). Mas Durkheim lembra que:

Só a história do ensino e da Pedagogia permite determinar as metas que a educação deve buscar a todo o momento, é na Psicologia que cabe procurar os meios necessários à realização destas metas (DURKHEIM, p. 95, 2013).

A Psicologia ajuda o pedagogo a situar-se em meio à multiplicidade de inteligências e caracteres (DURKHEIM, p. 95, 2013). Ainda o autor relaciona o ideal pedagógico de uma sociedade com o status vigente da própria organização social:

[...] o ideal pedagógico de uma época expressa antes de tudo o estado da sociedade na época considerada. Contudo para que este ideal se torne realidade, é preciso ainda fazer com que a consciência da criança se conforme a ele (DURKHEIM, p. 95, 2013).

Durkheim ainda descreve a relação entre a Pedagogia e a Sociologia, texto que integra a terceira e última parte de seu livro. Ele começa descrevendo a crença de que a Pedagogia e as práticas educativas deveriam apenas servir para que as aptidões humanas não se perdessem ou de alguma forma "atrofiassem" pela inatividade. Uma ideia de 
que "o educador nada teria a acrescentar à obra da natureza, não criando nada novo" (DURKHEIM, p. 100, 2013). Como é a Psicologia que tem a responsabilidade de descrever e explicar a individualidade humana, a concepção era a de que apenas ela bastaria à Pedagogia e à função do pedagogo (DURKHEIM, p. 100, 2013).

Mas é preciso observar a influência da sociedade na formação humana. Ela "não somente eleva o tipo humano à dignidade de modelo para o educador reproduzir, como também o constrói [...] de acordo com suas necessidades" (DURKHEIM, p. 107, 2013).

O homem que a educação deve realizar em nós não é o homem tal como a natureza criou, mas sim tal como a sociedade quer que ele seja; e ela quer que ele seja da forma exigida pela sua economia interior. A prova disto é a maneira como a concepção do homem variou conforme as sociedades (DURKHEIM, p. 107, 2013).

Para Durkheim o ideal pedagógico é fruto da sociedade sendo ela que "traça um retrato de homem" no qual se refletem as "particularidades de sua organização" (DURKHEIM, p. 108, 2013). O papel da sociedade sobre a educação é tão marcante que pode se observar a "iniciação" como elemento final da educação e rito de passagem para que o indivíduo possa ser inserido na sociedade ocupando um lugar específico (DURKHEIM, p. 111, 2013). A ideia clara de que a educação prepara seres humanos gerando seres sociais.

É este viés de inserção social que reforça a importância da Sociologia e que faz da Psicologia algo ainda necessário, mas insuficiente para a Pedagogia. É o conjunto de elementos sociais e da natureza humana que são necessários para que seja traçado um ideal de indivíduo (DURKHEIM, p. 113, 2013). O papel da sociologia, então, é determinar os fins que a educação deve buscar (DURKHEIM, p. 114, 2013).

[...] já que os fins da educação são sociais, os meios pelos quais estes fins podem ser alcançados devem necessariamente ter o mesmo caráter. E, de fato, dentre todas as instituições pedagógicas, talvez não haja nenhuma que não seja análoga a uma instituição social, cujos aspectos principais ela reproduz de forma reduzida em como que abreviada. Tanto na escola quanto na cidade, impõem-se uma disciplina. As regras que fixam os deveres dos alunos são comparáveis ás que prescrevem a conduta dos homens feitos (DURKHEIM, p. 116, 2013).

Émile Durkheim chama a atenção para que a Sociologia como ciência das instituições contribui para o entendimento do que são as de cunho pedagógico. Segundo ele, "quanto melhor conhecermos a sociedade, melhor perceberemos tudo o que se passa no microcosmo social que a escola é” (DURKHEIM, p. 117, 2013). Enquanto a 
Psicologia contribui para a Pedagogia em um nível que é o da subjetividade singular, a Sociologia contribui para o entendimento da dimensão coletiva.

Reside na perspectiva social as diretrizes que irão balizar um sistema educacional. Isto afetará diretamente a concepção dos métodos e a natureza das ações que serão impressas em termos de práticas educacionais.

Se a sociedade se orientar, por exemplo, em um sentido individualista, todos os processos educacionais que possam reprimir o indivíduo e ignorar sua espontaneidade interna serão considerados como intoleráveis e reprovados. Se ao contrário [...] ela sentir novamente a necessidade de impor um conformismo mais rigoroso a todos, será proibido tudo o que possa provocar além da conta a iniciativa da inteligência (DURKHEIM, p. 117, 2013).

Os métodos educativos sempre se transformaram a partir de correntes sociais que repercutiram em um âmbito da vida coletiva (DURKHEIM, p. 117, 2013). A mudança da estrutura social durante o Renascimento - por exemplo -, a então nova concepção de homem, pode servir de ilustração: a mudança metodológica, da abstração para o intuitivo (DURKHEIM, p. 118, 2013).

O fato é que a educação sempre busca atingir a coletividade a partir de reconstruções individuais. Seus meios, métodos e fins tentam satisfazer ideias e sentimentos coletivos. Embora a Psicologia ainda aponte ao pedagogo formas para agir sobre o indivíduo, é no estudo da sociedade que ele vai encontrar os princípios da sua investigação (DURKHEIM, p. 118, 2013). E a partir disto, Durkheim chama atenção para o fato de que as profundas transformações sociais da contemporaneidade tiveram reflexo direto sobre os sistemas educacionais (DURKHEIM, p. 119, 2013).

Durkheim encaminha o encerramento seu livro apregoando de maneira mais marcante a relevância da necessidade de se estudar a sociedade, de se compreender a importância de uma cultura sociológica para os educadores (DURKHEIM, p. 119-120, 2013). Para ele a sociologia pode fornecer um "corpo de ideias diretivas" que se constituem como "alma de nossas práticas". Isto resumiria toda a relação entre Educação e Sociologia, esta última dando um sentido dirigido a ação da primeira, como atividade essencial e sempre fecunda (DURKHEIM, p. 120, 2013).

Recebido em: junho/2015

Aceito em: dezembro/2015

\section{Endereço para correspondência:}

José Luís Schifino Ferraro

Av. Ipiranga, 6681 - Prédio 15

90619-900 Porto Alegre, RS, Brasil

<jose.1uis@pucrs.br> 